\title{
Sorbitol Transporter Expression in Apple Sink Tissues: Implications for Fruit Sugar Accumulation and Watercore Development
}

\author{
Zhifang Gao, Sastry Jayanty, Randolph Beaudry, and Wayne Loescher \\ Department of Horticulture, Michigan State University, East Lansing, MI 48824-1325
}

\begin{abstract}
In apple (Malus $\times$ domestica Borkh.), where sorbitol is a primary photosynthetic product that is translocated throughout the plant, accumulation of sorbitol in sink cells appears to require an active carrier-mediated membrane transport step. Recent progress in isolation and characterization of genes for sorbitol transporters in sour cherry (Prunus cerasus L.) and mannitol transporters in celery (Apium graveolens $\mathrm{L}_{\text {.) }}$ ) suggested that similar transporters may be present in apple tissues. A defect in these transporters could also explain the occurrence of the fruit disorder watercore, characterized by the accumulation of fluids and sorbitol in the apoplasmic free space. Our objectives therefore included isolation and characterization of genes for sorbitol transporters in apple tissues and comparisons of expression of transporter genes, especially in various sink tissues including watercored and non-watercored fruit tissues. We have isolated and characterized two sorbitol transporter genes, MdSOT1 and MdSOT2. Sequence analyses indicated that these are members of the major facilitator transporter superfamily that gives rise to highly hydrophobic integral membrane proteins. Heterologous expression and measurement of sorbitol uptake in yeast indicated that these are specific and with high affinities for sorbitol, with $\mathrm{K}_{\mathrm{m}} \mathrm{s}$ for sorbitol of 1.0 and $7.8 \mathrm{~mm}$ for MdSOT1 and MdSOT2, respectively. Sorbitol transporter expression was evident in all sink tissues tested with the exception of watercore-affected fruit tissues. Sorbitol accumulation in apple sink tissues thus involves an apoplasmic active membrane transport step and watercore results from a defect in that process.
\end{abstract}

Among tree fruits in the family Rosaceae, sorbitol is often the dominant, translocated photosynthetic product (Grant and ap Rees, 1981; Loescher and Everard, 2000). As in other crops (Gifford and Evans, 1981), defining the processes involved in partitioning of photosynthetic products in these plants is key to understanding sink strength and thus crop productivity and quality. In plants that primarily synthesize and transport sucrose, there are, for example, growth sinks (e.g., metabolically active meristems and synthesis of structural components), and there are also storage sinks accumulating starch [e.g., potato (Solanum tuberosum L.) and wheat ( Triticum aestivum L.)], lipid \{e.g., soybean [Glycine max (L.) Merr.]\}, hexoses [e.g., grape (Vitus vinifera L.)], or sucrose [e.g., sugarcane (Saccharum officinarum L.) and sugarbeet (Beta vulgaris L.)]. Similarly, in sorbitol synthesizers, sink activities include conversions of sorbitol to hexoses (e.g., apple) or starch [e.g., apple and peach (Prunus persica L.)], or storage of sorbitol [e.g., sweet cherry (Prunus avium L.) and sour cherry] (Loescher and Everard, 1996, 2000).

Several factors complicate understanding sink strength. No sink is exclusively one type throughout development. Thus there may be various correlations between growth or dry matter accumulation and activity of putative "rate-limiting" enzymatic steps [e.g., sucrose synthase, sucrose phosphate synthase, invertase(s), and ADP-glucose pyrophosphorylase as in potato tuber development (Fernie et al., 2002)], and all of these have been shown to be modulated by sugar levels in various systems (Koch, 1996). Among sorbitol synthesizers, sorbitol dehydrogenase is apparently ubiquitous, and in some species a sorbitol oxidase may also be important (Loescher and Everard, 2000). Further complications come from isoforms of sucrose synthase in the cytosol, acid invertases in cell walls and vacuoles, and neutral invertases in the cytosol (Sturm and Tang, 1999), and sorbitol dehydrogenase may also be present in multiple forms (Park et al., 2002)

Received for publication 13 May 2004. Accepted for publication 10 Aug. 2004. This research was supported by Project GREEEN and the Michigan Agricultural Experiment Station, both at Michigan State Univ.
Metabolite transport plays a critical step in partitioning. Due to analytical difficulties, however, membrane transporters have been less studied, but they are certainly not least in importance. Osmotically generated pressure flow requires solute import and export (i.e., phloem loading and unloading both require membrane transport). Although sucrose transporters have been extensively studied since the first of these was isolated and characterized (Riesmeier et al., 1992), relatively little is yet known about unloading and the expression and activity of membrane transporters in any sink tissues (Fillion et al., 1999; Lalonde et al., 2003; Patrick, 1997; Ruan and Patrick, 1995). Nonetheless, these must play critical roles in both phloem transport and in photosynthetic partitioning. As such, they are major determinants of plant productivity (Gifford and Evans, 1981).

Progress in understanding sorbitol transport has been quite limited. Although several sorbitol uptake experiments (Berüter, 1993; Berüter and Feusi, 1995; Kobashi et al., 2001; Marquat et al., 1997) suggested a carrier-mediated process, no sorbitol transporter had been cloned, and nothing was known of the molecular mechanisms involved. In one report, abscisic acid (ABA) and the sulfhydyl group modifier para-chloromercuribenzenesulphonic acid (PCMBS) affected uptake positively and negatively, respectively (Kobashi et al., 2001), but in another report, PCMBS and carbonyl cyanide 3-chlorophenylhydrazone (CCCP) had no effect (Berüter and Feusi, 1995). We have, however, recently cloned cDNAs from sour cherry encoding two distinct sorbitol transporters, and sorbitol uptake activity was characterized and confirmed by heterologous expression in yeast (Gao et al., 2003). In sour cherry, sorbitol and hexose accumulation were greatest later in stage III of fruit development, and both PcSOT1 and $P c A I$ (an acid invertase) were predominantly expressed at that time. Sorbitol transport is apparently mediated through PCSOTI and PCSOT2 in young and maturing cherry fruit tissues with these transporters playing a major role in sorbitol accumulation. $P c S O T 1$ is also expressed in expanding leaves before the sink to source transition is complete. 
One other report identifies and characterizes plant sorbitol transporters. In common plantain (Plantago major L.) source leaf companion cells, two sorbitol transporters (PmPLT1 and PmPLT2) have recently been isolated and characterized (Ramsperger-Gleixner et al., 2004). However, despite sequence similarities, both PmPLT1 and PmPLT2 are low-affinity $\left(\mathrm{K}_{\mathrm{m}} \mathrm{s}\right.$ of 12 and $20 \mathrm{~mm}$ ), low-specificity transporters and thus substantially different from the high-affinity, high-specificity PcSOTs. One plantain transporter is also PCMBS-sensitive, but the other is not (like the cherry SOTs). Since PCMBS sensitivity is often used to predict loading mechanisms, this confounds efforts to understand phloem loading in sorbitol transporting species.

A recent structural investigation (Zhang et al., 2004) indicates that phloem unloading in developing apple fruit is apoplasmic. There are several lines of evidence for this conclusion. Carboxyfluorescein dye remains confined in the phloem strands, a putative monosaccharide transporter is present on the plasma membrane of both sieve elements and parenchyma cells, a $\mathrm{H}^{+}$-ATPase is in the sieve element-companion cell complex, and uptake of ${ }^{14} \mathrm{C}$ labeled sorbitol as well as sensitivity of uptake to PCMBS and an ATPase inhibitor are consistent with these observations. Other evidence (Zhang et al., 2001) suggests that the unloading pathway of sucrose from the symplasmically isolated SE/CC complex may be predominantly apoplasmic in the developing apple fruit, and that the unloaded sucrose may be hydrolysed by the functional acid invertase localized in the cell wall before it is loaded in sink cells. Nonetheless, mechanisms of phloem loading and unloading of sugar alcohols, symplasmic or apoplasmic, are otherwise still not clear (Moing et al., 1997; van Bel, 1996). More information on sugar alcohol transporters and function is therefore essential to understanding the processes involved in phloem transport (both loading and unloading) and intracellular compartmentation and especially their roles in sink development and growth.

Another reason to study sorbitol transport is the potential relationship to the apple disorder watercore, which is characterized by fruit with water-soaked areas with elevated sorbitol levels, primarily in tissues adjacent to the vascular core. Most importantly, these symptoms develop only when fruit are attached to the tree, never after removal. Watercore can be a major problem in apple production and postharvest storage (watercored fruit cannot be stored because the water-filled free space leads to anaerobiosis, development of off-flavors, and early breakdown). There have been numerous explanations for the disorder (see review by Marlow and Loescher, 1984). There is certainly a genetic component (i.e., some cultivars are quite susceptible and others are totally resistant). However, in susceptible cultivars the only consistent explanation, but without experimental evidence, is a defect in sorbitol metabolism and/or transport. This relates to the elevated sorbitol content and to the disorder never appearing after removal from the tree. A decreased ability to transport sorbitol (into fruit storage parenchyma) would thus lead to sorbitol accumulation in the apoplast and to flooded tissues. An apoplastic transport step in phloem unloading and sink accumulation is also consistent with this explanation. Since isolation and characterization of genes for putative sorbitol transporters are now feasible, we can now test this hypothesis. Our objectives therefore include isolation and characterization of sorbitol transporters in apple sink tissues and comparisons of expression of transporters in sink tissues including watercored and non-watercored fruit tissues.

\section{Methods and Materials}

Plant material. Apple floral tissues ('McIntosh') were harvested from the Geneva Experiment Station, Geneva, N.Y., beginning 5 May 1997 at the bud stage halfway between tight cluster and pink. After pollination, fruit tissues were harvested frequently during stages of rapid development (through early June) and less frequently until ripening was imminent in early to mid-September, whereupon collection was twice weekly. Where possible, organs were segregated. Petal collection was between 5 and 27 May, anther collection was between 5 and 30 May, whole ovary (fruit) collection was between 5 May and 7 Oct., with fruit peels and cortex being segregated for collections between $18 \mathrm{Aug}$. and 7 Oct., and seed collection was between 18 June and 7 Oct. At each collection time, flowers or fruits were collected onto ice and transported immediately back to the lab. Flower and fruit tissues were segregated using a stainless steel surgical scalpel into liquid nitrogen and maintained at $-80^{\circ} \mathrm{C}$.

Apple fruit cortex and peel tissues were collected from the watercore-susceptible cultivar Winesap at the Clarksville Experimental Station, Michigan State Univ., Clarksville, during the 2002 season. Watercore-afflicted zones of cortex and peel tissue and healthy cortex and peel tissue of the same fruit and two different fruits were collected using a stainless steel surgical scalpel into liquid nitrogen and maintained at $-80{ }^{\circ} \mathrm{C}$.

Developing and mature leaves and phloem-and xylem-enriched tissues were obtained from apple trees ('Mutsu') growing at the Michigan State Univ. Horticultural Research and Teaching Facility in East Lansing. Elongating branches were collected onto ice and transported immediately back to the lab. Using procedures developed by Bieleski (1966), phloem- and xylem-enriched tissues were then segregated and stored in liquid nitrogen. Whole immature $(<1 \mathrm{~cm}$ long) to fully expanded leaves were collected from similar elongating branches and frozen in liquid nitrogen.

RNA EXTRACTION. Total RNA was extracted using a protocol developed by López-Gómez and Gómez-Lim (1992) and modified by Franke et al. (1995) for polysaccharide-rich tissues. Four to $6 \mathrm{~g}$ of tissue was ground to a fine powder in liquid nitrogen. Frozen tissue was placed in a liquid nitrogen cooled 50-mL conical polypropylene tube containing $0.25 \mathrm{~g}$ of PVPP (polyvinylpolypyrrolidone). Extraction buffer [Tris (150 mm), EDTA (ethylene diamine tetraacetic acid) (50 $\mathrm{mm}$ ), and SDS (sodium dodecyl sulfate) $(2 \%, \mathrm{w} / \mathrm{v})$ and mercaptoethanol $\left(2 \mu \mathrm{L} \cdot \mathrm{g}^{-1}\right.$ of fresh tissue $\left.)\right]$ was heated to $80^{\circ} \mathrm{C}$ and added to the frozen powder $(1: 3, \mathrm{w} / \mathrm{v})$ and vortexed briefly. This mixture was incubated at $65^{\circ} \mathrm{C}$ for 5 min with agitation. The homogenate was vortexed $(1 \mathrm{~min})$ with 0.25 volumes of ethanol and 0.11 volumes of potassium acetate (5 M). One volume of chloroform : isoamyl alcohol (49:1, v/v) was then added and vortexed ( $1 \mathrm{~min})$. The homogenate was then centrifuged $\left(6000 g_{\mathrm{n}}, 15 \mathrm{~min}\right)$ at room temperature, and the aqueous phase was extracted with 1 phenol: 1 chloroform. The homogenate was again centrifuged $\left(6000 g_{n}, 15 \mathrm{~min}\right)$ at room temperature and the aqueous phase transferred to a $30-\mathrm{mL}$ Corex tube. RNA was precipitated overnight at $20{ }^{\circ} \mathrm{C}$ with 0.6 volumes of $8 \mathrm{M} \mathrm{LiCl}$, centrifuged $\left(12,000 g_{\mathrm{n}}, 90 \mathrm{~min}\right)$ at $4{ }^{\circ} \mathrm{C}$, and then washed one time with $5 \mathrm{~mL} 70 \%$ ethanol. Further removal of polysaccharides involved several precipitations with salts and ethanol (Franke et al., 1995). For storage at $-80^{\circ} \mathrm{C}$, an RNA suspension was created by vortexing the solubilized RNA first with $20 \mu \mathrm{L} 3$ m sodium acetate and then with $650 \mu \mathrm{L} 100 \%$ ethanol. 
Cloning apple sorbitol transporters. The approach to clone apple sorbitol transporters was similar to the procedures described by Gao et al. (2003). A putative sorbitol transporter cDNA was amplified from a cDNA library for ripening apple fruit ('Mutsu') by RT-PCR. Degenerate primers were designed based on a sugar transporter region conserved among numerous plants (Noiraud et al., 2001). The primers were G62 \{forward 5'.. GA(A/G)TC(T/C/A/G)CC(T/C/A/G)CG(T/C/A/G)TGGCT..3' $\left.{ }^{\prime}\right\}$ and G60 \{reverse $5^{\prime} . . \mathrm{CG}(\mathrm{T} / \mathrm{C} / \mathrm{A} / \mathrm{G}) \mathrm{CC}(\mathrm{T} / \mathrm{C}) \mathrm{TG}(\mathrm{T} / \mathrm{C} / \mathrm{A} / \mathrm{G}) \mathrm{GT}(\mathrm{T} /$ C) TC(T/C)GG..3'\}. The forward primer corresponds to a ESPRWL conserved motif, and the reverse primer to a RGQTEP conserved motif. This cDNA was cloned to pGEM easy vector (Promega, San Luis Obispo, Calif.) according to the manufacturer's instructions and sequenced. The cDNA was then used as a probe to screen $\approx 4 \times 10^{5}$ recombinant phages from an apple fruit cDNA library constructed in Lambda Zap Express (Stratagene, La Jolla, Calif.) according to the manufacturer's instructions. The apple fruit cDNA library was constructed from tissues pooled at different stages of fruit ripening from the cultivar Mutsu and was generously provided by Drs. D. Dilley and I. Wilson (Michigan State Univ., East Lansing). Putative MdSOT clones were isolated and sequenced at the Genomics Technology Support Facility at Michigan State Univ.

EXPRESSION AND CHARACTERIZATION OF MDSOT1 ANDMDSOT2

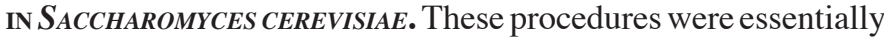
identical to those of Gao et al. (2003). The full length cDNAs of MdSOT1 and MdSOT2 were ligated into the EcoRI-XhoI sites of the yeast shuttle vector pDR196 (Rentsch et al., 1995). This vector allows expression of full-length cDNA under the control of the S. cerevisiae PMA1 promoter. The $S$. cerevisiae strain RS 453 (Sauer and Stadler, 1993), which lacks the uracil gene for selection of recombinant cells, was transformed with the pDR196 plasmid containing $M d S O T 1$ and $M d S O T 2$ according to the method of Dohmen et al. (1991). Cells transformed with empty pDR196 plasmid were used as controls.

UPTAKe OF RADIOLABELED SORBitol. Sorbitol uptake into transformed yeast cells was followed as described by Noiraud et al. (2001). To measure the $\mathrm{K}_{\mathrm{m}}$ values of MdSOT1 and MdSOT2, sorbitol concentrations of $0.1,0.2,0.5,1,2,4,8$, and $12 \mathrm{~mm}$ and an uptake time of 2 or 4 min were used. All the uptake experiments were repeated at least four times with the pDR 196 empty vector transformed cells as controls.

RNA GEL-BLOT HYBRIDIZATION. Total RNA, $20 \mu \mathrm{g}$, was typically separated on a $1.3 \%$ agarose gel under denaturing (formaldehyde) conditions. RNA was then capillary transferred (Sambrook and Russell, 2001) to Hybond-N nylon membranes (Amersham, San Francisco, CA) overnight in 20× SSC and fixed to the membrane at $80^{\circ} \mathrm{C}$ for $1.5 \mathrm{~h}$. A DNA probe was prepared by PCR and the primers were 5'-TGGGCCATCGTGTTGTGC-3 and a T3 Promoter Sequencing Primer (5'-ATTAACCCTCACTAAAGGGA-3') for MdSOT2. Random priming for ${ }^{32} \mathrm{P}$-labeling used a NEBlot kit (New England Biolabs, Beverly, Mass.) according to the manufacturer's instructions. Membranes were hybridized and washed with low-salt buffer as previously described (Gao and Loescher, 2000). The mRNA abundances were captured on a PhosphorImaging screen (Molecular Dynamics, Sunnyvale, Calif.). The same blots were washed at $90{ }^{\circ} \mathrm{C}$ for $30 \mathrm{~min}$ in a solution containing $0.2 \%$ SDS, $0.5 \mathrm{~mm}$ Tris $\mathrm{pH} 7$, and $0.1 \mathrm{~mm}$ EDTA to strip off the probes, and rehybridized with a ${ }^{32} \mathrm{P}-$ labeled probe of 18S rRNA from arabidopsis [Arabidopsis thaliana $(\mathrm{L}$. Heynh.] to standardize for RNA loading
For tissue prints, fruits were collected in early June, hand sectioned with a razor blade, blotted briefly with a Whatman $3 \mathrm{M}$ filter paper, and then blotted with pressure onto a Hybond-N nylon membrane for $30 \mathrm{~s}$. Membranes were soaked in alkaline solution containing $1.5 \mathrm{M} \mathrm{NaCl}$ and $0.5 \mathrm{M} \mathrm{NaOH}$ for $2 \mathrm{~min}$, neutral solution containing $1.5 \mathrm{M} \mathrm{NaCl}$ and $0.5 \mathrm{~m}$ Tris $\mathrm{pH} 8.0$ for $4 \mathrm{~min}$, and 0.2 м Tris (pH 7.5) for $30 \mathrm{~s}$. The membranes were dried at $80{ }^{\circ} \mathrm{C}$ for $1.5 \mathrm{~h}$ and otherwise hybridized and washed as above.

Naming of MdSOT1 and MdSOT2 followed a search of the Mendel CPGN database, and no MdSOT synonyms exist. The cDNAs reported in this paper have been deposited into Genbank with the following accession numbers: AY237400 for MdSOT1 and AY237401 for MdSOT2. A BLAST (National Center for Biotechnology Information, Bethesda, Md.) search revealed a number of sequences similar to MdSOT1 and MdSOT2. These were further analyzed using a Lasergene software package (DNASTAR, Madison, Wis.). Selected plant sugar alcohol, hexose, and sucrose transporter sequences were assembled and edited with EditSeq and SeqMan, aligned with MegAlign, and a phylogram was constructed to illustrate relative similarities.

Sugar ANALYSES. Sugars were extracted from subsamples of the same watercored and control cortical and peel tissues used for RNA extractions and analyzed using standard procedures (Gao and Loescher, 2003). Briefly, sugars and sugar alcohols were converted to the oximes, silylated, and then analyzed with a gas chromatograph equipped with a DB-17 capillary column (J\&W Scientific, Folsom, Calif.) and a flame ionization detector.

\section{Results}

CDNA CLONING AND SEQUENCING. To identify potential apple sorbitol transporters, we used RT-PCR and degenerate primers corresponding to conserved regions of "sugar transporters." A cDNA fruit library screen isolated seven positive clones, and cDNA sequence results show three putative sorbitol transporters. Two of the clones were likely full-length cDNAs encoding ORFs of putative sorbitol transporters (based on similarities to sour cherry transporters). Figure 1 compares the derived amino acid sequences of five sugar alcohol transporters (two apple sorbitol transporters, two cherry sorbitol transporters, and a celery mannitol transporter). All are quite similar. Indeed, BLAST results (data not shown) for the sugar alcohol transporter nucleic acid sequences indicated that these were essentially identical (Evalues were all zero), especially in comparison to other sugar transporters. A phylogram was constructed from a DNAStar Lasergene MegAlign ClustalW alignment of a number of sugar alcohol and sugar transporter nucleic acid sequences (Fig. 2). These 16 nucleic acid sequences are divided into three major subgroups. MdSOT1 and MdSOT2 are quite similar to other sugar alcohol transporters that have been functionally characterized (i.e., the celery mannitol transporters Matl and Mat2, the cherry sorbitol transporters PcSOT1 and PcSOT2, and the plantain sorbitol transporters $p l t 1$ and plt2). These sugar alcohol transporters are, however, distinctly different from the plant sucrose, inositol, and hexose transporters selected for this analysis. Nonetheless, like the cherry sorbitol (Gao et al., 2003) and the celery mannitol transporters (Noiraud et al., 2001), the sequence similarities (data not shown) also indicate that MdSOT1 and MdSOT2 are clearly members of the major facilitator superfamily (Chang et al., 2004; Marger and Saier, 1993). Similarly, hydrophobicity analyses (data not shown) indicate that, like the disaccharide and monosaccharide 
PCSOT1 MTDRRAQ-DNAVSGQPLLKK-------KPKRNLYA IGCA ILASMTSILLGYDIGVMSGASIYIQKDLKISDVEVEILIGILNLYSLIGSAA 83 PCSOT2 MADRRAEYNAVVSGQPQKNIADFDP PGKPKRNKYAFACAILASMTS ILLGYDIGVMSGAVIYIKKDLKVSDVEIEVLVGILNLYSLIGSAA 91 MdSOT1 M--

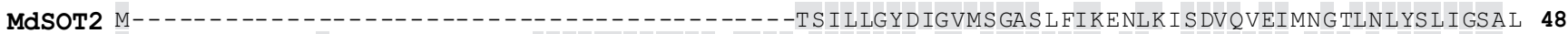
AgMaT1 M--------ITGEVSVDSYDTNKP-KPKRNKYAFACALLASMNS I LLGYDGVLSGASIYIKEDLHFSDVQIEIIIGIINIYSLLGSAI 80

PCSOT1 AGRTSDWIGRRYTIVFAGA IFFTGALLMGLATNYAFLMVGRFVAGIGVGYALMIAPVYNAEVSPASSRGALTSFPEVFVNIGILLGYVANY 174 PCSOT2 AGRTSDWIGRRYTIVLAGA I FAGALLMGFAPNYAFLMFGRFVAGIGVGYALMIAPVYTAEVSPASSRGFLTSFPEVFINAGILFGYVSNY 182 MdSOT1 AGKTSDWVGRRYTIVISGA I FFIGA I LMGF STNYTFLMC GRFVAGIGVGYALTIAPVYSAEVSPTSSRGFLTSFPEVFVNIGILLGYLSNY 139 MdSOT2 AGRTSDWI GRRYTIVLAGT IFFIGALLMGFAPNYAFLMFGRFVAGVGVGYALMIAPVYTAEISPASFRGFLTSFPEVFVNIGILLGYVSNY 139 AgMaT1 AGRTSDWI GRRYTMVLAGI I FFLGA I FMGLATNFAFLMFGRFVAGI GVGYAMMI APVYTAEVAPSSSRGFLTSFPEVF INSGVLLGYVSNF 171

PCSOT1 AFSGLPIDLGWRLMLGVGVFPSVILAVGVLSMPES PRWLVMQGRLGEAKQVLDKT S DSLEEAQLRLADIKEAAG IPEHCVEDVVQVPKHSH 265 PCSOT2 GFSKLPTHLGWRLMLGVGA I PSI F LA IGVLAMPES PRWLVMQGRLGDARKVLDKT S DSLEESKLRLGE I KEAAG IPEHCNDD IVEVKKRSQ 273 MdSOT1 AFSFCPLDLGWRLMLGVGA I P SVGLAVGVLAMPESPRWLVMQGRLGEAKRVLDRTS DSKEESMLRLADIKEAAGIPEECNDDIVQVSGHSH 230 MdSOT2 AFSKLP I H LNWR I MLGVGAFPSVI LAVGVLAMPES PRWLVMQGRLGDAKRVLQKTSESIEECQLRLDDIKEAAG IPKESNDDVVQVSKRSH 230 AgMaT1 AFAKCPLWLGWR IMLG I GAFPSVALA I IVLYMPESPRWLVMQGRLGEARTVLEKTSTSKEEAHQRLSDIKEAAG IDKDCNDDVVQVPKRTK 262

PCSOT1 GEEVWKELLLHPTPPVRHILIAAIGFHFFQQLSGIDALVLYSPRIFEKAGITDSSTLLLATVAVGFSKTIFTLVAIGFLDRVGRRPLLLTS 356 PCSOT2 GQEVWKQLLLRPTPAVRHI LMCAVGLHFFQQASGI DAVVLYSPRI FEKAGITNPDHVLLCTVAVGFVKTVFILVATFMLDRIGRRPLLLTS 364 MdSOT1 GEGVWKELLVHPTPTVRHILIAAIGFHFFQQASG I DA LVLYSPRVFAKAGITSTNQLLLCTVGVGLSKTVFTLVATFFLDRVGRRPLLLTS 321 MdSOT2 GEGVWKE LLLHPTPAVRHILIAALG I HFFEQSSG I DSVVLYSPRIFEKAGITSYDHKLLATVAVGVVKTICILVATVFLDKFGRRPLLLTS 321 AgMaT1 DEAVWKELILHPTKPVRHAAITGIGI HFFQQACGIDAVVLYSPRIFEKAGIKSNSKKLLATIAVGVCKTVFILISTFQLDKIGRRPLMLTS 353

PCSOT1 VAGMIASLLCLGTSLT IVDHETE-KMMWA SVLCLTMVLAYVGFFS I GMGP IAWVYSSEIFPLKLRAQGCSMGTAVNR IMSGVLSMSF ISLY 446 PCSOT2 VAGMVF T LACLGLGLT I IDHS GE-K I MWA I ALS L TMV LA YVAF FS I GMGP I TWVYSSEI F P LQLRAQGCS IGVAVNRVVSGVLSMTF IS LY 454 MdSOT1 MAGMVGALVCLGTSLTIVDQHEGVRMTWAVILCLCCVLAYVGFFSSGIGP I AWVYSSEI FPLRLRAQGCGMGVAVNRLMSG I LSMTF IS LY 412 MdSOT2 VAGMVF S L SCLGASL T IVDQQHG-K I MWA I VLC I TMV L LNVAF FS I GLGP I TWVYSSEI F P LQLRAQGCSMGVAVNRVT SGV I SMT F IS LY 411 AgMaT1 MGGMVIALFVLAGSLTVINKSHHTG-HWAGGLA I FTVYAFVS I FSS GMGP I AWVYSSEVFP LRLRAQGCS IGVAVNRGMSG I I GMTF ISMY 443

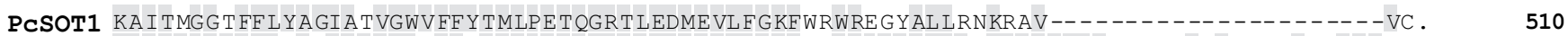
PCSOT2 KAITIGGAFFLFAAIAAVGWTFFFTMLPETQGRTLEDMEVLFGKFYRWRKANALLKQKKQVDHGD-GNNNPNNPQIQLGTKGQAN. 539 MdSOT1 KAITMGGTFFLYAAI GTVGWIFFFTMLPETQGRTLEDMEVLFGKFHKWRKANKLLEKKKRVAHGDIGTSDPDNRAHLLA. MdSOT2 KAITIGGAFF LYAGI AAVGWVFFYMLYPETQGRTLEDMEVLFGKYHKWREANALLQKAKQVDGDD-------------KGQVH . AgMaT1 KAMTIGGAFLLFAVVAS IGWVFMYTMFPETQGRNLEE IELLFGSYFGWRKTLKDLKAKE--------AAEAKSRESEV.

Fig. 1. A comparison of the deduced amino acid sequences of the cDNAs of five sugar alcohol transporters (two apple sorbitol transporters, MdSOT1 and MdSOT2; two cherry sorbitol transporters, PcSOT1 and PCSOT2; and a celery mannitol transporter, AgMaT1). Shaded sequences are identical.

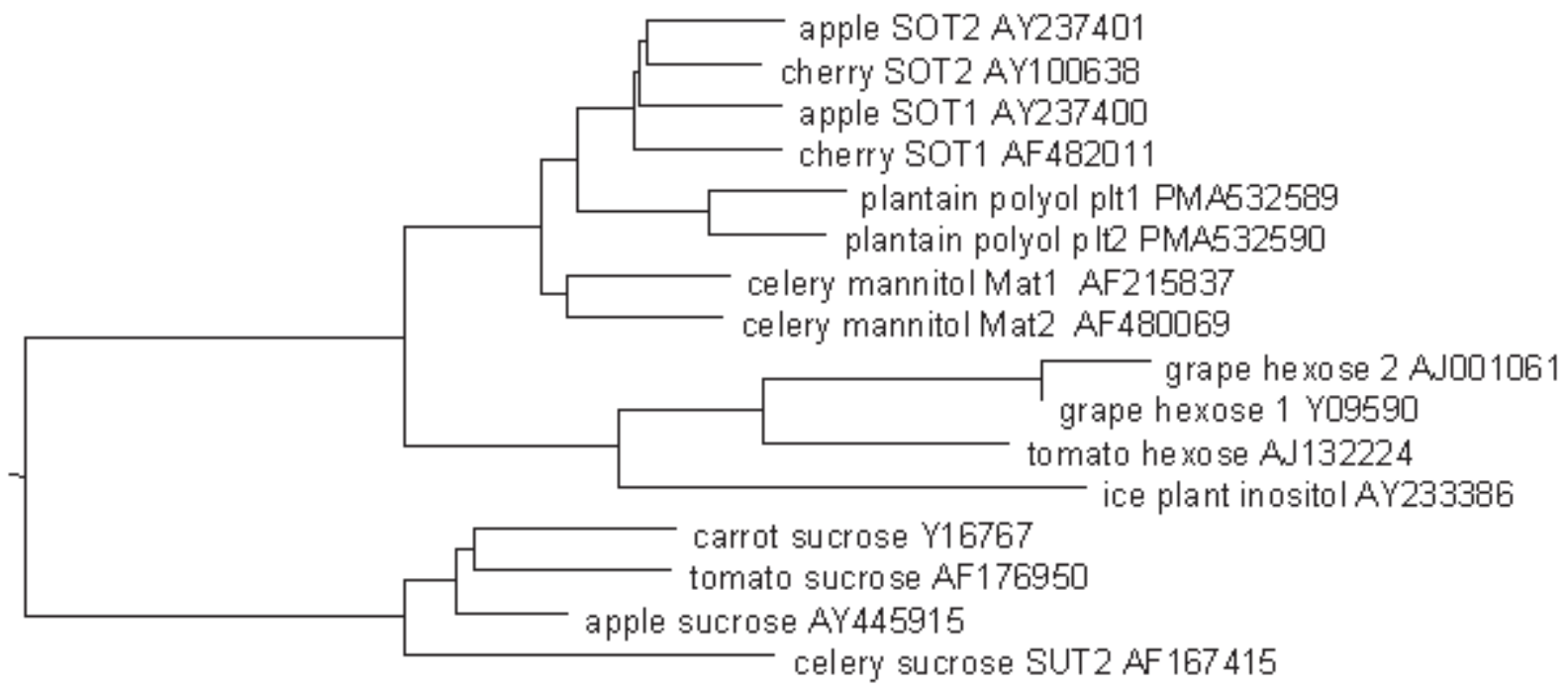

Fig. 2. A phylogram (a cladogram where branch distances to correspond to sequence divergence) constructed from a DNASTAR Lasergene MegAlign ClustalW alignment of sugar alcohol and selected sugar transporter nucleic acid sequences from apple (Malus $\times$ domestica Borkh.), carrot (Daucus carota L.), celery (Apium graveolens L.), sour cherry (Prunus cerasus L.), grape (Vitis vinifera L.), ice plant (Mesembryanthemum crystallinum L.), plantain (Plantago major L.), and tomato (Lycopersicon esculentum L.). The analyzed sequences (identified by common name, material transported, and accession number) divide into three major subgroups with the apple sorbitol transporter sequences, MdSOT1 and MdSOT2, closest to other functionally characterized sugar alcohol transporters that are all distinctly different from the sucrose, inositol, and hexose transporters. 
transporters, these all are highly hydrophobic integral membrane proteins with 11 , possibly 12 , transmembrane domains, depending on the prediction program used (Gao et al., 2003).

KINETICS. Following expression in yeast, sorbitol uptake was measured over time, as a function of concentration. Uptake was linear with time (Fig. 3) and on a cell/protein basis (data not shown), and with typical Michaelis-Menten kinetics (Fig. 4). $\mathrm{K}_{\mathrm{m}} \mathrm{s}$ for sorbitol were 1.0 and $7.8 \mathrm{~mm}$ for MdSOT1 and MdSOT2, respectively.

EXPRESSION ANALYSES. Northern blots of extracts from flowers (petals, anthers and young ovaries) indicated substantial expression (Fig. 5). Fruit tissue extracts showed that transporters were expressed throughout fruit development (data not shown). MdSOT1 and MdSOT2 genes were also expressed in leaf tissues and in epidermal, phloem-, and xylem-rich extracts from young twigs (Fig. 6). Tissue prints/blots showed that expression was highest in young fruit in cortical tissues and particularly in seed coats (Fig. 7). In mature fruits, expression was high in both the cortex and epidermis of non-watercored fruit tissues, but was low in both afflicted (the vascular core) and nonafflicted tissues of watercored fruit (Fig. 8).

COMPOSITIONAL ANALYSES. Sugar and sorbitol compositions of watercored and non-watercored fruit were consistent with a number of previous reports of watercore symptoms (Marlow and Loescher, 1984). Sorbitol was a minor component in non-watercored fruit tissues, but a major component in watercored tissues (Fig. 9).

\section{Discussion}

Evidence here for sorbitol transporter gene expression in fruit and other apple sink tissues indicates that sorbitol accumulation in these tissues involves an active carrier-mediated process. Based on characterization by means of heterologous expression in yeast, MdSOT1 and MdSOT2 transporter kinetics and specificity are also consistent with what should be expected for an apoplastic step in the unloading processes (Lalonde et al., 2003). These apple sorbitol transporters are also similar to previously analyzed plant sugar transporters, particularly the cherry sorbitol transporters, and the plantain sorbitol transporters, and the celery mannitol transporter (i.e., they are energy-dependent $\mathrm{H}^{+}$symporters driven by the proton motive force across the plasma membrane) (Ramsperger-Gleixner et al., 2004). Furthermore, sorbitol transporter expression in various reproductive tissues (e.g., seedcoats, petals, anthers, and ovaries) is clearly associated with flower development, fruit growth, and fruit sugar accumulation. Expression of these transporter genes in these tissues, like the occurrence of various enzymes of sorbitol and sucrose metabolism, is therefore another indicator of sink activity. Although sorbitol does not invariably accumulate in sink tissues (i.e., it may be only a minor component of young fruit tissues and other actively growing meristematic tissues), it can accumulate to high levels, especially in bark and wood of dormant apple tissues, conditions that also suggest active accumulation against a concentration gradient. In those tissues where sorbitol and sugar accumulation can be quite substantial (e.g., in sweet and sour cherry fruit storage parenchyma) (Gao et al., 2003; Roper et al., 1987), transporter activity is clearly a major indicator of sink strength and activity. However, whether uptake is a rate-limiting and controlling step in fruit growth and development remains to be determined.

Although kinetics and specificity are otherwise consistent with an active transport process in sink tissues, the relatively low expression of MdSOT1 and MdSOT2 in source tissues (i.e.,

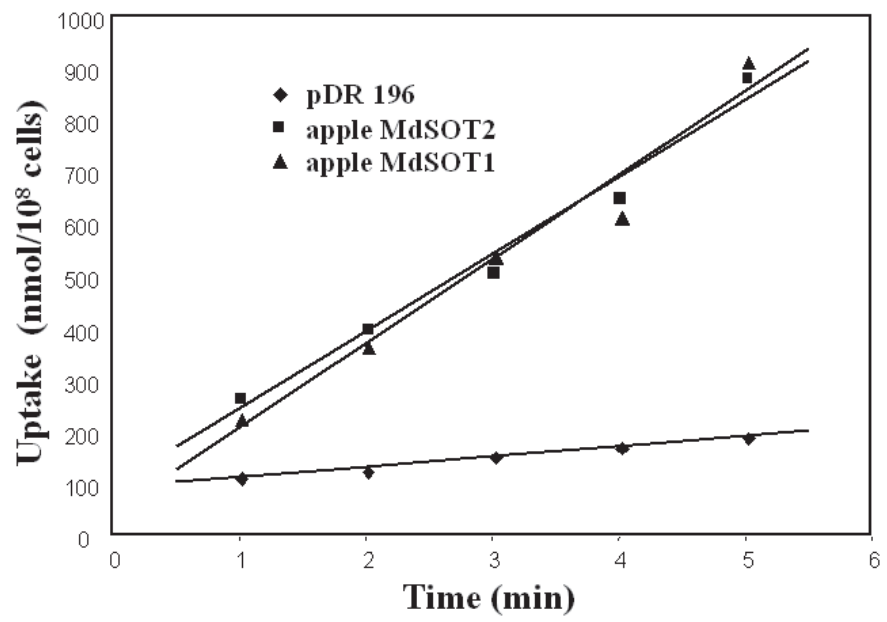

Fig. 3. Uptake of ${ }^{14} \mathrm{C}$-sorbitol by yeast cells expressing MsSOT1, MsSOT2, or the empty vector control.
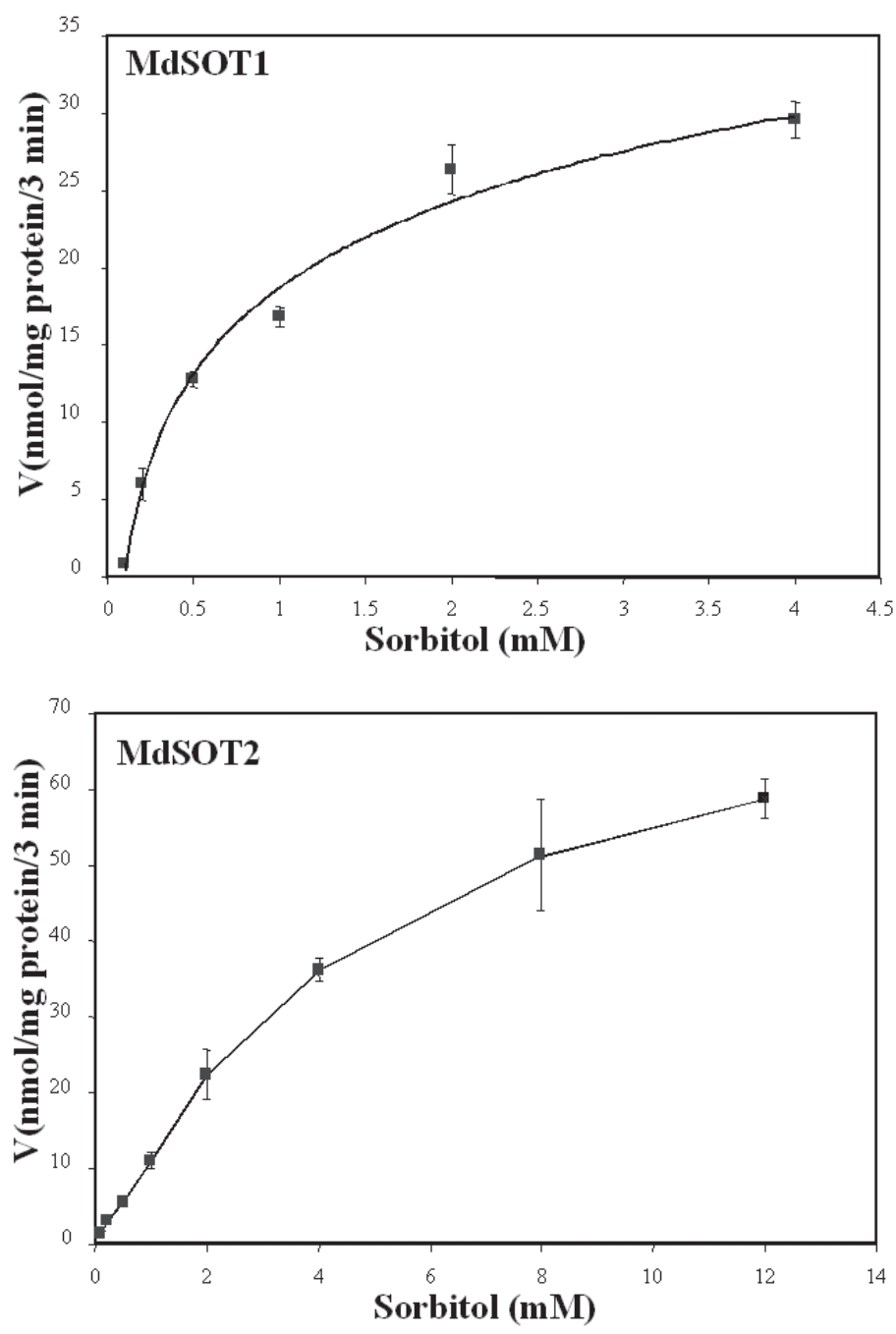

Fig. 4. Uptake of ${ }^{14} \mathrm{C}$-sorbitol by yeast cells expressing either (A) MSSOT1 and (B) MsSOT2, showing typical Michaelis-Menten kinetics. $\mathrm{K}_{\mathrm{m}} \mathrm{s}$ for sorbitol, 1.0 and $7.8 \mathrm{~mm}$ for MdSOT1 and MdSOT2, respectively, were derived from Eadie-Hofstee plots of these same data . 


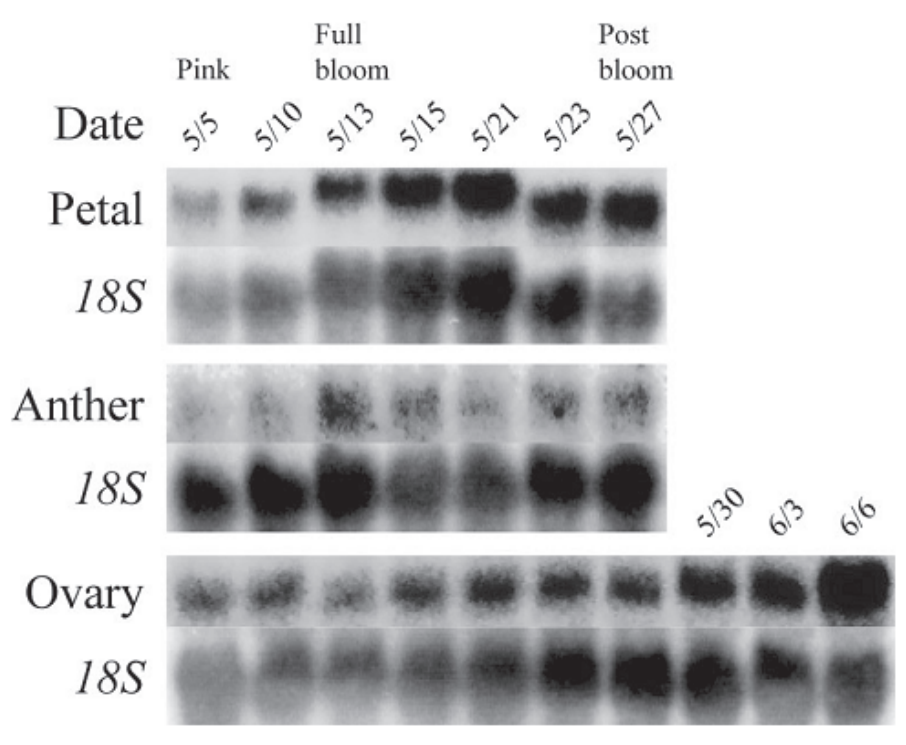

Fig. 5. Northern mRNA blots showing MdSOT gene expression in extracts from flowers (petals, anthers, and young ovaries).

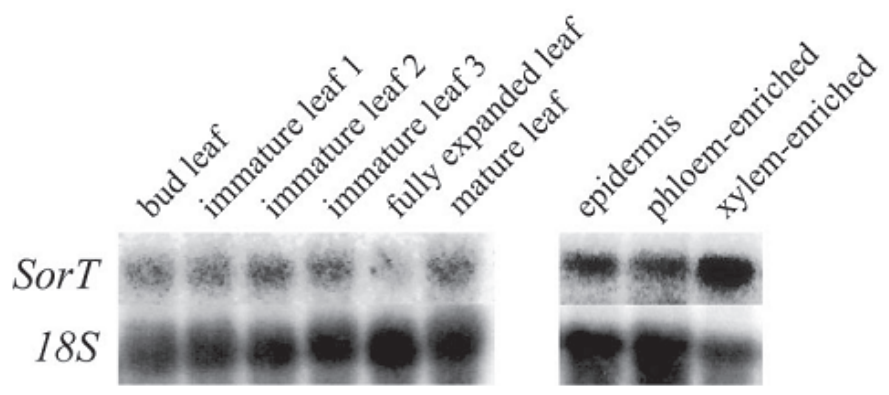

Fig. 6. Northern RNA blots showing accumulation of MdSOT transcripts, gene expression, in leaf tissue extracts [immature leaves 1, 2, and 3 differ only in stage of development (i.e., from one quarter to half to three quarters full length)], and epidermal, phloem-, and xylem-rich extracts from young twigs.

fully expanded and mature leaves) suggests that these particular sorbitol transporters are unlikely candidates for a major role in phloem loading. Low leaf expression may, however, be evidence that these transporters are limited to expression in vascular tissues. Alternatively, quite similar transporters may be involved, or phloem loading in apple may involve a symplasmic component, in which case active phloem loading may be only a minor contributor to source leaf transport processes. Expression in stem tissues [i.e., epidermal and phloem- and xylem-enriched samples (Fig. 7)], however, suggests that these transporters may play a role in retrieval of solutes leaked to the surrounding apoplasm (Lalonde et al., 2003). All this requires further study. Indeed, despite recent progress, van Bel's comment (1996) is still appropriate: “The mode and mechanism of phloem loading (and unloading) of sugar alcohols is obscure. The minor vein configuration of the families (e.g., Rosaceae, Apiaceae), in which polyols occur in significant quantities in mesophyll and phloem sap (Loescher et al.. 1992; Redgwell and Bieleski, 1978; Rumpho et al., 1983; Zimmerman and Ziegler. 1975), suggests that sugar alcohols are loaded apoplasmically. On the other hand, mannitol (Flora and Madore, 1993) and dulcitol (Zimmermann and Ziegler, 1975) have been found to be translocated in the phloem sap together with galactosyl oligosaccharides, supposedly indicative of symplasmic phloem loading.” Recent structural studies (Zhang et al., 2001, 2004) do,

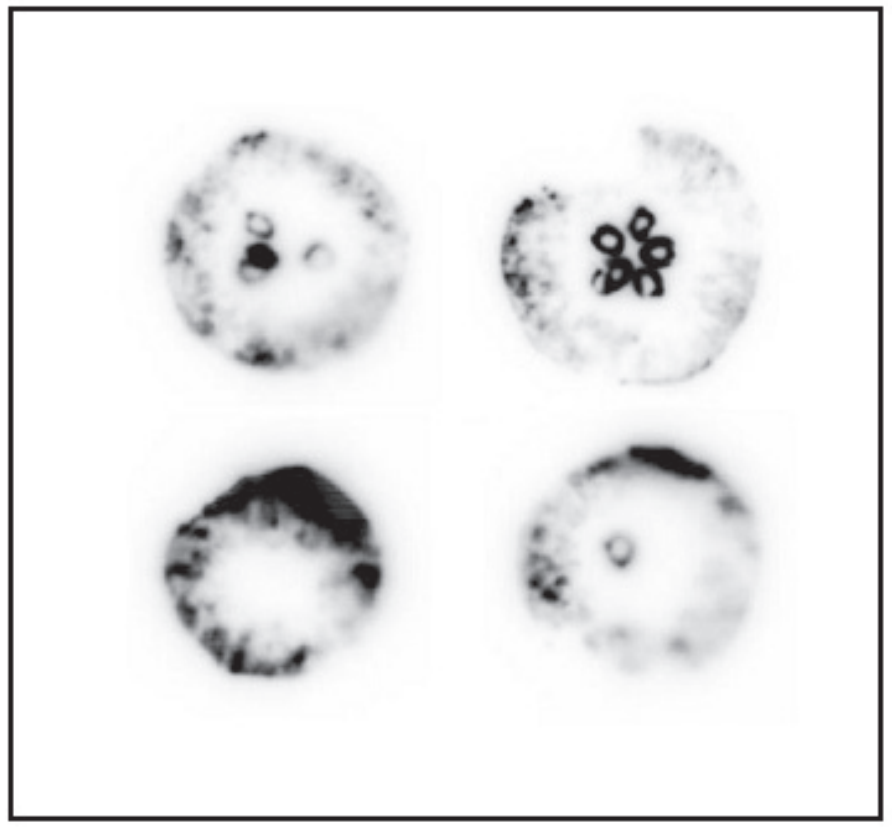

Fig. 7. Tissue prints (Northern blots) of different transverse sections of young apple fruits, with MdSOT expression highest in young fruit in cortical flesh tissues and particularly in seedcoats. Multiple sections are shown since seeds were not always present in the sections sampled.

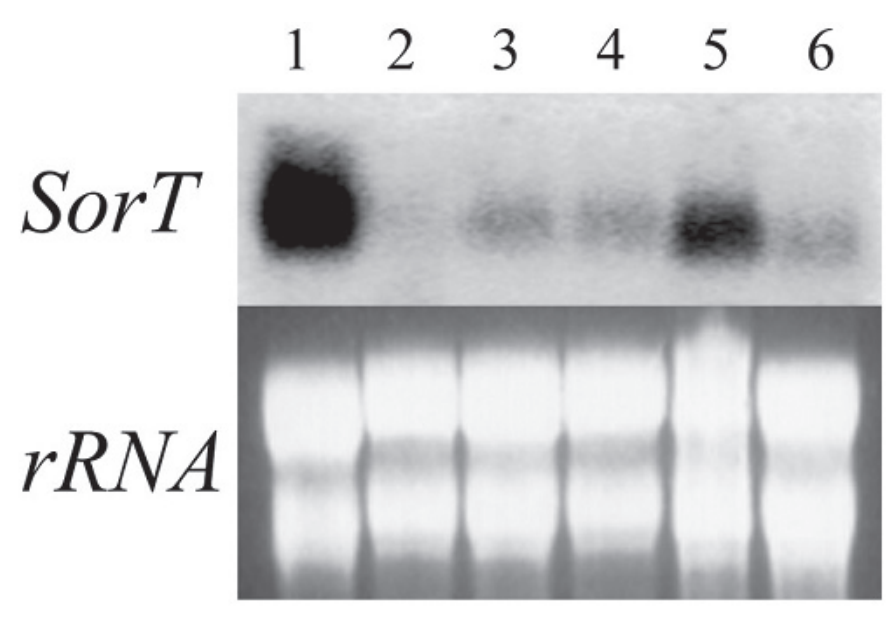

Fig. 8. (Upper panel) Northern blots of mature fruit tissue RNA extracts showing that MdSOT expression was high in both the cortex and epidermis of nonwatercored fruit tissues, but was low in both afflicted (the vascular core) and nonafflicted tissues of watercored fruit. Lane 1. RNA from healthy apple cortex tissues, no symptoms; Lane 2. RNA from water core affected cortex (different fruit); Lane 3. RNA from symptomless cortex, watercored fruit; Lane 4. RNA from watercored cortex (same fruit as 3); Lane 5. RNA healthy fruit peel (same fruit as 1); Lane 6. RNA affected fruit peel (same fruit as 3). (Lower panel) ethidium bromide stained gels of these same samples.

however, indicate an apoplasmic step in unloading, although the mechanisms specifically involved in sorbitol unloading are not yet structurally resolved.

Sorbitol transporter expression is also quite low in watercored apple peel and cortical tissues and especially when compared to healthy unaffected fruit. This suggests some developmental or ripening related regulation of transporter expression, with implications for fruit quality and postharvest physiology. Although these watercore data are derived from only one cultivar and additional 


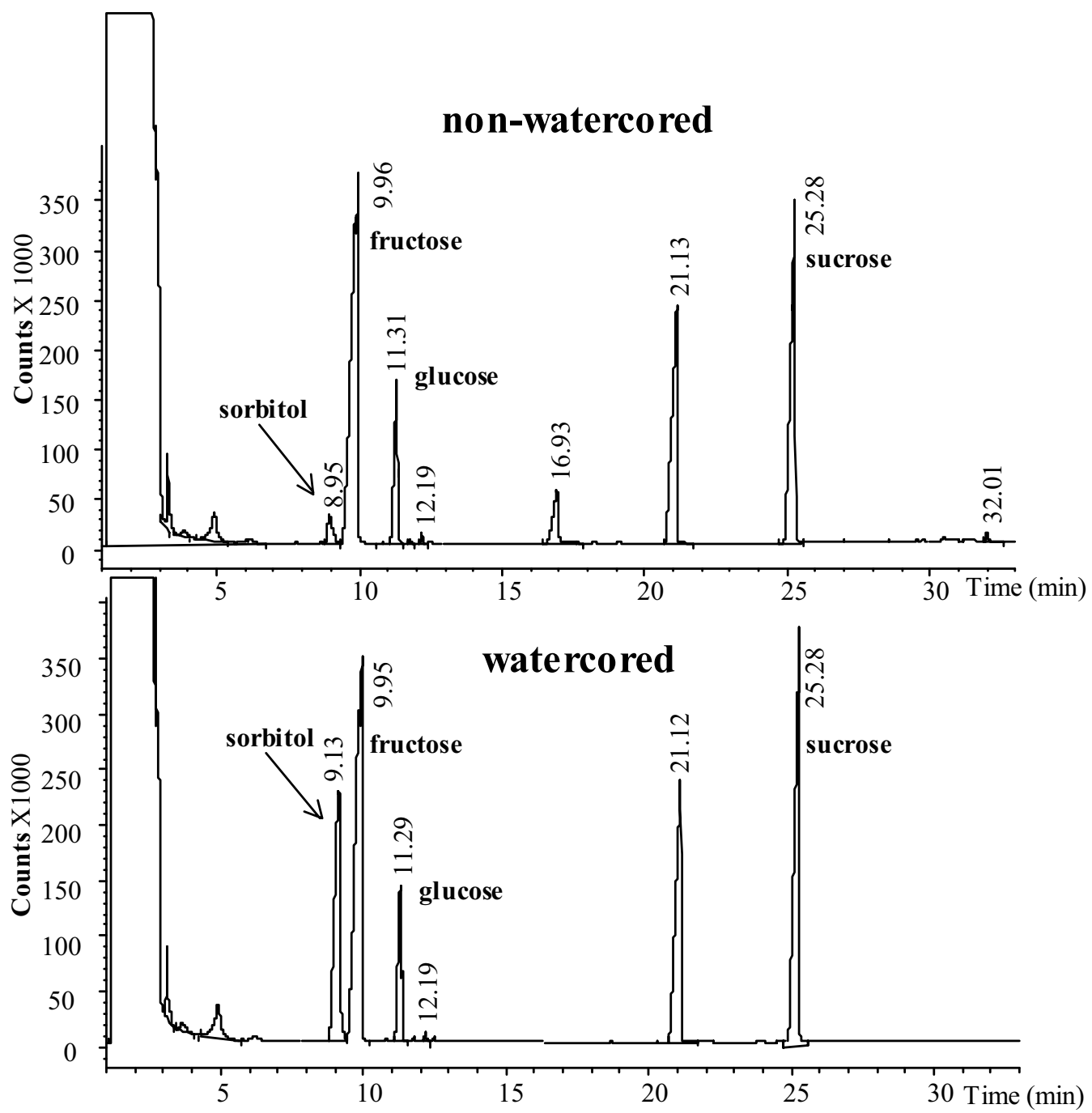

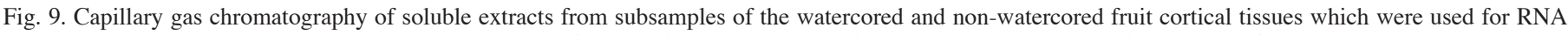
extractions showing that there were only trace amounts of sorbitol in non-watercored tissues in contrast to the sorbitol content of watercored tissues.

susceptible and resistant cultivars will need to be studied, these results are nonetheless consistent with the hypothesis that a decreased ability to transport sorbitol into fruit storage parenchyma tissues would lead to sorbitol accumulation in the intercellular space and then to flooded tissues (due to apoplastic solute concentrations). Most importantly, the conclusion that accumulation of sorbitol in sink tissues involves an apoplastic active transport step is also entirely consistent with this scheme.

\section{Literature Cited}

Berüter, J. 1993. Characterization of the permeability of excised apple tissue for sorbitol. J. Expt. Bot. 44:519-528.

Berüter, J. and M.E.S. Feusi. 1995. Comparison of sorbitol transport in excised tissue discs and cortex tissue of intact apple fruit. J. Plant Physiol. 146:95-102.

Bieleski. R.L. 1966. Sites of accumulation in excised phloem and vascular tissues. Plant Physiol. 41:455-466.

Chang, A.B., R. Lin, W.K. Studley, C.V. Tran, and M.H. Saier. 2004. Phylogeny as a guide to structure and function of membrane transport proteins. Mol. Membrane Biol. 21:171-181.

Dohmen, R.J., A.W.M. Strasser, C.B. Honer, and C.P. Hollenberg. 1991. An efficient transformation procedure enabling long-term storage of competent cells of various yeast genera. Yeast 7:691-692.

Fernie,A.R.,L. Willmitzer, and R.N. Trethewey. 2002. Sucrose to starch:A transition in molecular plant physiology. Trends Plant Sci. 7:35-41.

Fillion, L., A. Ageorges, S. Picaud, P. Coutos-Thévenot, R. Lemoine, C. Romieu, and S. Delrot. 1999. Cloning and expression of a hexose transporter gene expressed during the ripening of grape berry. Plant Physiol. 120:1083-1093.

Flora, L.L and M.A. Madore. 1993. Stachyose and mannitol transport in olive (Olea europaea L). Planta 189:484-490.

Franke, K.E., Y. Liu, and D.O. Adams. 1995. Yield and quality of RNA from grape berries at different developmental stages. Amer. J. Enol. Viticult. 46:315-31

Gao, Z. and W.H. Loescher. 2000. NADPH supply and mannitol biosynthesis. Characterization, cloning, and regulation of the non-reversible glyceraldehyde-3-phosphate dehydrogenase in celery leaves. Plant Physiol. 124:321-330

Gao, Z. and W.H. Loescher. 2003. Expression of a celery mannose 6phosphate reductase in Arabidopsis thaliana enhances salt tolerance and induces biosynthesis of both mannitol and a mannitol-glucose dimer. Plant Cell Environ. 26:275-283

Gao, Z., L. Maurousset, R. Lemoine, S.-D. Yoo, S. van Nocker, and W.H. Loescher. 2003. Cloning, expression, and characterization of sorbitol transporters from developing sour cherry (Prunus cerasus) fruit and leaf sink tissues. Plant Physiol. 131:1566-1575. 
Gifford, R.M. and L.T. Evans. 1981. Photosynthesis, carbon partitioning, and yield. Annu. Rev. Plant Physiol. Plant Mol. Biol. 32:485-509.

Grant, C.R. and T. ap Rees. 1981. Sorbitol metabolism by apple seedlings. Phytochemistry 20:1505-1511.

Kobashi, K., S. Sugaya, H. Gemma, and S. Iwahori. 2001. Effect of abscisic acid (ABA) on sugar accumulation in the flesh tissue of peach fruit at the start of the maturation stage. Plant Growth Regulat. $35: 215-223$

Koch, K.E. 1996. Carbohydrate-modulated gene expression in plants. Annu. Rev. Plant Physiol. Plant Mol. Biol. 47:509-540

Lalonde, S., M. Tegeder, M. Throne-Holst, W.B. Frommer, and J.W. Patrick. 2003. Phloem loading and unloading of sugars and amino acids. Plant Cell Environ. 26:37-56.

Loescher, W.H., R.H. Tyson, J.D. Everard, R.J. Redgwell, and R.L. Bieleski. 1992. Mannitol synthesis in higher plants: Evidence for the role and characterization of a NADPH-dependent mannose 6-phosphate reductase. Plant Physiol. 98:1396-1402.

Loescher, W.H. and J.D. Everard. 1996. Sugar alcohol metabolism in sinks and sources, p. 185-207. In: E. Zamski and A.A. Schaffer (eds.). Photoassimilate distribution in plants and crops. Marcel Dekker, New York.

Loescher, W.H. and J.D. Everard. 2000. Regulation of sugar alcohol biosynthesis, p. 275-299. In: R.C. Leegood, T.D. Sharkey, and S. von Caemmerer (eds.). Photosynthesis: Physiology and metabolism. Kluwer, Dordrecht, The Netherlands.

López-Gómez, R. and M.A. Gómez-Lim. 1992. A method for extracting RNA from fruits rich in polysaccharide using ripe mango mesocarp. HortScience 27:440-442.

Marger, M.D. and M.H. Saier. 1993. A major superfamily of transmembrane facilitators that catalyse uniport, symport and antiport. Trends Biochem. Sci. 18:13-20.

Marlow, G. and W.H. Loescher. 1984. Watercore. Hort. Rev. 6:189251.

Marquat, C., G. Petel, and M. Gendraud. 1997. Saccharose and sorbitol transporters from plasmalemma membrane vesicles of peach tree leaves. Biol. Plant. 39:369-378.

Moing, A., F. Carbonne, B. Zipperlin, L. Svanella, and J.P. Gaudillere. 1997. Phloem loading in peach: Symplastic or apoplastic? Physiol. Plant. 101:489-496.

Noiraud, N., L. Maurousset, and R. Lemoine. 2001. Identification of a mannitol transporter, AgMaT1, in celery phloem. Plant Cell 13:695-705.

Park. S.W., K.J. Song, M.Y. Kim, J.H. Hwang, Y.U. Shin, W.C. Kim, and W.I. Chung. 2002. Molecular cloning and characterization of four cDNAs encoding the isoforms of NAD-dependent sorbitol dehydrogenase from the Fuji apple. Plant Sci. 162:513-519.

Patrick, J.W. 1997. Phloem unloading: Sieve element unloading and post-sieve element transport. Ann. Rev. Plant Physiol. Plant Mol.
Biol. 48:191-222.

Ramsperger-Gleixner, M., D. Geiger, R. Hedrich, and N. Sauer. 2004. Differential expression of sucrose transporter and polyol transporter genes during maturation of common plantain companion cells. Plant Physiol 134:147-160.

Redgwell, R.J. and R.L. Bieleski. 1978. Sorbitol-1-phosphate and sorbitol-6-phosphate in apricot leaves. Phytochemistry 17:407-409

Rentsch, D., M. Laloi, I. Rouhara, E. Schmelzer, S. Delrot, and W. B. Frommer. 1995. Ntr1 encodes a high-affinity oligopeptide transporter in arabidopsis. FEBS letters 370:264-268.

Riesmeier, J.W., L. Willmitzer, and W.B. Frommer. 1992. Isolation and characterization of a sucrose carrier cDNA from spinach by functional expression in yeast. EMBO J. 11:4705-4713.

Roper,T.R., W.H. Loescher, J. Keller, and C.R. Rom. 1987. Sources of photosynthate for fruit growth in 'Bing' sweet cherry. J. Amer. Soc. Hort. Sci. 112:808-812.

Ruan, Y-L and J.W. Patrick. 1995. The cellular pathway of postphloem sugar transport in developing tomato fruit. Planta 196:434-444.

Rumpho, M.E., G.E. Edwards, and W.H. Loescher. 1983. A pathway for photosynthetic carbon flow to mannitol in celery leaves: Activity and localization of key enzymes. Plant Physiol 73:869-873.

Sambrook, J., and D.W. Russell. 2001. Molecular cloning: A laboratory manual, $3^{\text {rd }}$ ed. Cold Spring Harbor Laboratory Press, Cold Spring Harbor, N.Y.

Sauer, N. and R. Stadler. 1993. A sink-specific $\mathrm{H}^{+} /$monosaccharide co-transporter from Nicotiana tabacum: Cloning and heterologous expression in baker's yeast. Plant J. 4:601-610.

Sturm, A. and G.Q. Tang. 1999. The sucrose-cleaving enzymes of plants are crucial for development, growth and carbon partitioning. Trends Plant Sci. 4:401-407.

van Bel, A.J.E. 1996. Carbohydrate processing in the mesophyll trajectory in symplasmic and apoplasmic phloem loading. Progress Bot. 57:140-167.

Zhang, D.P., Y.M. Lu, Y.Z. Wang, C.Q. Duan, and H.Y. Yan. 2001. Acid invertase is predominantly localized to cell walls of both the practically symplasmically isolated sieve element/companion cell complex and parenchyma cells in developing apple fruits. Plant Cell Environ. 24:691-702.

Zhang, L.Y., Y.B. Peng, S. Pelleschi-Travier, Y. Fan, Y.F. Lu, Y.M. Lu, X.P. Gao, Y.Y. Shen, S. Delrot, and D.P. Zhang. 2004. Evidence for apoplasmic phloem unloading in developing apple fruit. Plant Physiol. 135:574-586.

Zimmerman, M.H. and H. Zeigler. 1975. List of sugars and sugar alcohols in sieve-tube exudates, p. 480-503. In: M.H. Zimmerman and J.A. Milburn (eds.). Transport in plants. Encycl. Plant Physiol. vol. 1. New Ser. Springer-Verlag, New York. 